\title{
EDUCAÇÃO DO CAMPO E DESAFIOS AMAZÔNICOS: \\ o PRONERA no Estado do Amapá
}

\author{
Heliadora Georgete Pereira da Cost a ${ }^{1}$ \\ Rony Mayer Lomba²
}

\section{RESUMO}

O texto objetiva analisar os resultados da pesquisa sobre os Programas de Educação do Campo no Estado do Amapá, dentre estes, o Programa Nacional de Educação na Reforma Agrária (PRONERA), que apoia projetos conveniados com a Secretaria de Estado da Educação (SEED), o Instituto Federal de Educação do Amapá (IFAP) e a Universidade Federal do Amapá (UNIFAP). É uma abordagem qualitativ a, de caráter descritivo e interpretativo, que utiliza a pesquisa bibliográfica para subsidiar a revisão de literatura e a coleta de dados realizada a partir da análise documental, que rev elam todo o processo de materialização do programa e a sua relevância no atendimento educacional aos trabalhadores dos assentamentos da Reforma Agrária no Estado do Amapá.

Palavras-chave: Pronera. Educação do Campo. Reforma Agrária.

\section{COUNTRYSIDE EDUCATION AND AMAZON CHALLENGES:}

\section{the PRONERA in State Amapá}

\begin{abstract}
This paper aims to analyze the survey results on the field of Education Programs in the State of Amapá, among them, the National Education Program in Agrarian Reform (PRONERA), which supports insured projects with the State Department of Education (SEED), the Federal Institute of Amapá Education (IFAP) and the Federal University of Amapá (UNIFAP). It is a qualitative descriptive and interpretative character, which uses bibliographical research to support the literature review and data collection. It was performed from the analysis of documents that reveal the entire process of realization of the program and its relevance in the education service to workers' settlements of Agrarian Reform in the State of Amapá.
\end{abstract}

Keywords: Pronera. Countryside Education Land Reform. Agrarian Reform.

\footnotetext{
1 Mestra em Desenvolvimento Regional - Universidade Federal do Amapá (UNIFAP). Pedagoga e Especialista em Gestão Escolar. Funcionária Pública da Educação. Membro da Cátedra Paulo Freire da Amazônia-UNIFAP/UEAP. E-mail: heliadoracosta@gmail.com

2 Doutor em Geografia, docente do curso de Geografia na Universidade Federal do Amapá (UNIFAP), docente no Programa de Mestrado em Desenvolvimento Regional da UNIFAP. E-mail: ronimayer@hotmail.com
} 


\section{EDUCACION DEL CAMPO Y DESAFÍOS AMAZÓNICOS: \\ el PRONERA en el Estado de Amapá}

\section{RESUMEN}

El texto tiene como objetivo analizar los resultados de la investigación sobre los Programas de Educacion del Campo em El Estado de Amapá, entre ellos, El Programa de Educacion em la Reforma Agraria (PRONERA), que apoya proyetos convenio com la Secretaría de Estado de Educacion (SEED), el Instituto Federal de Educación de Amapá (IFAP) y la Universidad Federal de Amapá (UNIFAP). Es um abordaje cualitativo, de caráter descriptivo e interpretativo, que utiliza la inv estigación bibliográfica para subsidiar la revisión de literatura y la recolección de datos realizada a partir del análisis documental, que revelan todo El processo de materialización del Programa y su relevancia em la atención educativa a los trabajadores de los asentamientos del la Reforma Agraria en el Estado de Amapá.

Palabras clave: Pronera. Educación del Campo. Reforma Agraria.

\section{INTRODUÇÃO}

O contexto de gênese do Programa Nacional de Educação na Reforma Agrária (PRONERA) foi marcado pelo fortalecimento dos movimentos sociais do campo e por intensos conflitos entre camponeses e latifundiários. Diante disso, na década de 1990, os movimentos sociais pressionaram o Estado brasileiro, a fim de inserir a discussão sobre a Reforma Agrária e a elaboração de políticas sociais específicas para os povos do campo na agenda do governo.

O aumento das ocupações de terras provocou muitos conflitos no campo. O governo de Fernando Henrique Cardoso estabeleceu, então, o Plano de Reforma Agrária em 1995, cuja finalidade definida no documento, era assentar duzentas e oitenta mil famílias, mas ao lado disso, o Estado também atendia aos interesses dos latifundiários, aumentando os conflitos com os trabalhadores rurais, principalmente, os sem terra, uma vez que o referido plano não conseguiu atingir a meta estabelecida.

Entre os conflitos que marcaram esse período, os massacres de Corumbiara, estado de Rondônia (1996) e de Eldorado dos Carajás, no Pará (1997), ganharam notoriedade devido à forte violência contra trabalhadores 
do campo e isso conduziu o governo a criar o Ministério Extraordinário de Política Fundiária (MEPF).

Diante desses conflitos, em 1998, O Movimento dos Trabalhadores Rurais Sem Terra (MST) promoveu a Marcha Nacional por Reforma Agrária, Emprego e Justiça, que recebeu o apoio da sociedade civil e demonstrou a insatisfação com a política econômica e social que vinha sendo implantada no País, além de fazer frente à ofensiva neoliberal que procurava combater e criminalizar os movimentos do campo. Todavia, os movimentos sociais conseguiram importantes conquistas e o MST teve grande ascensão nesse período, uma vez que continuava com o processo de resistência contra os grandes latifundiários e mediante tal fato reivindicava a distribuição de terras para os trabalhadores rurais.

A falta de políticas públicas para atender as necessidades dos trabalhadores do campo é expressão clara de uma política neoliberal, baseada na lógica de mercado, o que também está relacionado ao projeto de desenvolvimento adotado no Brasil, que é, predominantemente, um modelo urbano em que camponeses, indígenas, quilombolas, ribeirinhos, caiçaras e os demais povos do campo são vistos como espécies em extinção.

Diante da inexistência de políticas públicas, os movimentos sociais passaram a reivindicar a Reforma Agrária associada à garantia de direitos sociais. Ainda nos anos de 1990, inúmeros eventos, como congressos pela Reforma Agrária, foram desenvolvidos e as discussões pela distribuição de terras desencadearam a necessidade de lutar pela garantia de direitos básicos entre os quais a habitação, a saúde, a educação, dentre outros.

A educação dos trabalhadores rurais passou então a fazer parte das estratégias para alcançar a Reforma Agrária, uma vez que buscava-se o fortalecimento da luta por direitos. Assim, as reivindicações pela implantação de escolas no campo foram vinculadas aos movimentos sociais camponeses. 
Nesse contexto de luta pela terra e diante da necessidade de educação para os sujeitos do campo, nasceu o Pronera, que é uma política de educação elaborada pelos movimentos sociais durante o I Encontro Nacional de Educadores da Reforma Agrária (I ENERA). Neste evento, os movimentos sociais tiveram espaço para compartilhar experiências educativas que vinham desenvolvendo fora do encargo do Estado e solicitar a efetivação de uma política educacional adequada ao campo (CAMACHO, 2014).

O Pronera foi aprovado pela Portaria $n^{\circ} .10$ de 16 de abril de 1998, do Ministério Extraordinário da Política Fundiária (MEPF), atual Ministério do Desenvolvimento Agrário (MDA), ficando vinculado ao Gabinete do Ministro. Este programa constitui-se como uma experiência que vai além da oferta de escolarização para a população dos assentamentos, sendo na concepção de Andrade e Di Pierro (2004, p. 13) "[...] um instrumento da estratégia de democratização do acesso à terra e desenvolvimento rural sustentado por meio da Reforma Agrária".

As parcerias articuladas durante o I ENERA e a mobilização social foram ações importantes para a consolidação do Pronera como política pública de educação para a população assentada. Conforme o item I da Portaria No. 10/98, o PRONERA tem como objetivo "fortalecer a educação nos projetos de assentamentos de Reforma Agrária, utilizando metodologias específicas para o campo, que contribuam para o desenvolvimento rural sustentável das áreas de assentamentos".

O programa é voltado para o financiamento de projetos que contemplem a escolarização e a formação dos trabalhadores assentados "[...] nos níveis do ensino básico, superior e pós-graduação, Residência Agrária, modalidade de jovens e adultos, Educação do Campo, curso técnico profissional de nível médio" (BRASIL/PRONERA, 2014, p. 12). Diante disso, as secretarias municipais e estaduais, os institutos federais e as universidades são parceiros no desenvolvimento de projetos de formação apoiados pelo Pronera. 
Este artigo está sistematizado, considerando uma breve reflexão sobre o contexto histórico do Pronera, procurando compreender a importância dos movimentos sociais na luta pela melhoria da educação do campo no âmbito nacional; no segundo momento apresenta as discussões sobre o desenvolvimento de projetos conveniados pelo Pronera no Amapá, partindo dos dados coletados durante a pesquisa de campo e a análise documental.

O objetivo deste estudo é apresentar reflexões sobre as práticas pedagógicas nos projetos conveniados pelo Pronera no Estado do Amapá.

\section{PRONERA: contexto histórico}

O Pronera vem contribuindo para democratizar o acesso à Educação Básica e Superior aos sujeitos do campo. Conforme expõe Camacho (2014, p. 437):

Com a grande quantidade de projetos que foram desenvolvidos a partir do PRONERA, em diferentes níveis de escolarização e em parceria com diferentes instituições e movimentos sociais e sindicais, este programa faz avançar o debate da Educação do Campo.

De acordo com Molina (2003), o Pronera passou por etapas distintas desde a sua aprovação. Conforme afirma a autora, entre o período de criação em 1997 até o ano de 2003, o programa passou por três fases que expressaram o cenário político e as lutas dos movimentos sociais, principalmente do MST, na elaboração, expansão e gestão de recursos. Foi o período de efervescência e forte articulação dos movimentos sociais, o que contribuiu para que este programa se firmasse como política pública de educação do campo.

$\mathrm{Na}$ fase de implantação, o Pronera enfrentou dificuldades na liberação de recursos financeiros para que as turmas iniciassem as aulas, mas a pressão dos movimentos sociais e a intensa mobilização nos assentamentos contribuíram para dar início aos projetos de Educação de Jovens e Adultos (EJA). Além disso, enfrentou-se inúmeras divergências de interesses políticos, como afirma Molina (2003, p. 56-57): 
A cada ano a Comissão Pedagógica e os movimentos sociais negociavam e principalmente articulavam-se com deputados e senadores para garantir recursos do Orçamento da União ao Programa. Assim foi, desde o início, o PRONERA. Como em 1998 era um ano eleitoral para a Presidência, e como estratégia de campanha, o governo anunciou que o PRONERA alfabetizaria em um ano, 200 mil trabalhadores rurais. [...] Quando este foi lançado advieram divergências entre o Ministério de Desenvolvimento Agrário (à época o Extraordinário de Política Fundiária) e o da Educação. [...] Como existiu intensa mobilização nacional em assentamentos e universidades para começarem os projetos de alfabetização, a demora estava causando desgaste político e um descrédito ao Programa. Passado o mês, o governo federal não cumpriu o acordo. O MST e seu Setor de Educação organizaram acampamentos em mais de 20 estados, nas sedes das superintendências do Incra, montando aí salas de aula com assentados, realizando atividades de formação. Com esta pressão, o MEPF remanejou recursos de sua competência e liberou três milhões de reais para se iniciar $O$ PRONERA. A Comissão Pedagógica Nacional decidiu começar somente projetos na frente de Educação de Jovens e Adultos, de demanda maior. Foram assinados os primeiros oito convênios para alfabetizar sete mil trabalhadores rurais.

A partir de 2001, as tensões internas nos órgãos co-responsáveis pelo Pronera ficaram acirradas. Sob a gestão do INCRA, foi aprovado um novo Manual de Operações para o programa, através da Portaria $n^{\circ}$. 837. Nesse período, houve a diminuição da cooperação dos parceiros e os movimentos sociais perderam espaço na definição, na coordenação e na gestão nacional do Programa, que ficou subordinado à Coordenação de Projetos Especiais do INCRA. Ele teve o seu organograma modificado, permanecendo assim até o ano de 2002, correspondendo ao segundo período do programa apontado por Molina (2003).

Segundo Hage (2013, p. 03):

O fato de O PRONERA ter sido concebido fora do âmbito governamental imprimiu-lhe inicialmente um modelo de gestão tripartite em que representantes do governo compartilhavam decisões estratégicas e pedagógicas com representantes das universidades e dos movimentos sociais (Di Pierro, 2001). No entanto, no ano de 2001, o Programa é incorporado ao Instituto Nacional de Colonização e Reforma Agrária (INCRA), passando assim, a depender de aval das instâncias superiores do mesmo e não mais da Coordenação Geral de Projetos Especiais da Superintendência do Desenvolvimento Agrário. 
Após as eleições presidenciais de 2002, o Pronera recebeu um novo organograma e os movimentos sociais, as universidades e demais parceiros retomaram a participação no programa. Para Molina (2003), o terceiro período do Pronera começou em 2003, com a nova gestão do INCRA, que vinculou o Programa ao Gabinete da Presidência do Instituto.

Com a continuidade do governo Lula, em 2004, o Pronera foi adequado às novas demandas que surgiram a partir da oferta de Educação Básica para os trabalhadores dos assentamentos. Com isso, o Manual de Operações do Pronera passou por novas alterações, a fim de ser adequado à proposta do governo, que tinha a educação como prioridade e objetivava aumentar o número de matrículas em todos os níveis.

Nesse contexto, o Manual de Operações de 2004 inseriu o Pronera na Educação Superior, estabelecendo novas diretrizes e orientações sobre a função das universidades na oferta de cursos com base em demandas para o programa. O referido manual concebia, ainda, as atribuições do Estado e dos movimentos sociais sobre o Pronera.

Dentre os princípios apontados neste novo Manual de Operações encontram-se:

[...] parceria é a condição para a realização das ações do PRONERA. Os principais parceiros são os movimentos sociais e sindicais de trabalhadores e trabalhadoras rurais, $O$ INCRA, as instituições públicas de ensino, as instituições comunitárias de ensino sem fins lucrativos e os governos municipais e estaduais. Na parceria, - PRONERA se desenvolve por meio de uma gestão participativa, cujas responsabilidades são assumidas por todos(as) em uma construção coletiva na elaboração dos projetos, no acompanhamento e na avaliação (BRASIL, 2004, p.18).

De acordo com o Manual de Operações (2004), os cursos de Ensino Superior ofertados pelas universidades em parceria com o Pronera eram destinados à formação profissional, devendo atender os níveis de graduação e pós-graduação dentro das diferentes ciências. Com esta proposta vislumbrava-se o desenvolvimento sustentável dos assentamentos por meio da qualificação dos sujeitos. 
O Decreto $n^{\circ}$. 7.352, de 04 de novembro de 2010, que dispõe sobre a Política Nacional de Educação do Campo e sobre o Pronera amplia a oferta do Programa. Segundo Hage (2013, p. 5) a partir do referido decreto "[...] o Pronera inicia sua transição de uma ação de governo para se tornar política pública de caráter permanente".

O Art. $1^{\circ}$ do Decreto $n^{\circ} .7 .352 / 2010$ define que:

A política de educação do campo destina-se à ampliação e qualificação da oferta de educação básica e superior às populações do campo, e será desenvolvida pela União em regime de colaboração com os Estados, o Distrito Federal e os Municípios, de acordo com as diretrizes e metas estabelecidas no Plano Nacional de Educação e o disposto neste Decreto (BRASIL, 2010).

Além disso, foram definidos os conceitos de educação e população do campo, assim como os objetivos, os beneficiários, os níveis de escolaridade e a forma de gestão do Pronera. Assim, o Programa passou a ter a garantia de oferta pelo Estado brasileiro e os movimentos sociais conseguiram fazer avançar as discussões sobre a necessidade de assegurar o direito à educação e democratizar o acesso ao conhecimento para os povos do campo, pois:

[...] O Pronera, enquanto política pública é uma experiência inovadora, na medida em que foi implantada num território marcado historicamente pela exclusão social e ausência de políticas públicas na área da educação (CAMACHO, 2014, p. 443).

Para Molina (2003), mesmo diante dos conflitos e embates políticos nos primeiros anos de implantação, o Pronera conseguiu se estabelecer como política de educação voltada para a Reforma Agrária, uma vez que "[...] o programa funciona como uma espécie de indutor da própria reflexão e de muitas ações da Educação do Campo" (CAMACHO, 2014, p. 431).

Para Molina e Jesus (2011), um dos princípios do Pronera é a oferta de cursos que promovam 0 desenvolvimento dos assentamentos e a transformação na realidade social do aluno, o que é um desafio, sendo que a: 
Parte maior deste desafio é a compreensão de que esta contribuição só se efetiva à medida que os cursos promovam também a ampliação da consciência e da prática dos educadores e educandos dos cursos vinculados ao Programa, na perspectiva da transformação do modelo hegemônico de desenvolvimento do campo vigente no Brasil (MOLINA e JESUS, 2011, p. 34).

Em nível nacional, o Pronera operacionaliza projetos nas diferentes áreas e níveis de ensino, o que é apontado como resultado favorável à democratização do acesso e à escolarização dos trabalhadores dos assentamentos da Reforma Agrária. De acordo com o Manual de Operações (2004, p. 18), entre os princípios políticos e pedagógicos do Pronera está a "[...] ampliação do número de pessoas alfabetizadas e formadas em diferentes níveis de ensino, e do número de educadores, de técnicos/ agentes mobilizadores nas áreas de Reforma Agrária".

Neste sentido, o Pronera objetiva facilitar o acesso dos assentados à educação formal, aumentando as perspectivas de que os sujeitos podem contribuir na construção de um novo modelo de desenvolvimento para o campo. Além disso, o referido Programa imprime a esperança de ressignificação do campo e a superação da visão dicotômica entre o rural e o urbano, o campo e a cidade, sendo a formação dos trabalhadores um processo importante na luta pela conquista e garantia de direitos.

\section{PRONERA NO AMAPÁ: desafios e possibilidades}

No Estado do Amapá, o Pronera financiou projetos coordenados pela Secretaria de Estado da Educação (SEED) entre os anos de 2001 e 2012. O projeto Saber Mais, Viver Melhor-Pronera resultou do convênio firmado entre o INCRA e a SEED no ano de 2001 e tinha como objetivo a alfabetização de jovens e adultos assentados da Reforma Agrária.

De acordo com o Manual de Operações do Pronera (2011, p. 15), a preocupação inicial do programa foi com o alto índice de analfabetismo entre a população jovem e adulta dos assent amentos da Reforma Agrária: 
Examinadas as possíveis linhas de ação, decidiu-se dar prioridade à questão do analfabetismo de jovens e adultos, sem ser excluído o apoio a outras alternativas. As razões para essa opção foram: o alto índice de analfabetismo e os baixos níveis de escolarização entre os beneficiários do Programa de Reforma Agrária.

Diante desta determinação, os projetos de escolarização apoiados pelo Pronera tinham como foco a educação de jovens e adultos a ser ofertada nos assentamentos, com a finalidade de minimizar as defasagens educativas dos trabalhadores assentados e acampados da Reforma Agrária.

No convênio citado, o Pronera foi coordenado pela Divisão de Educação de Jovens e Adultos (DIEJA) da SEED. Conforme consta nos relatórios, o projeto foi elaborado com a participação dos movimentos sociais do campo do Amapá, sendo Rede de Escolas-Família do Amapá (RAEFAP), Federação dos Trabalhadores da Agricultura do Amapá (FETAGRAP), Superintendência Regional do INCRA, Central Única dos Trabalhadores (CUT), Comissão Pastoral da Terra (CPT), Movimento de Assentados e Associação de Assentados (MAAP), Ministério do Desenvolvimento Agrário (MDA). Para Andrade e Di Pierro (2004, p. 22), "Os movimentos sociais respondem pela mobilização das comunidades, enquanto as Superintendências do INCRA desempenham funções de acompanhamento financeiro, apoio logístico e articulação interinstitucional".

$\mathrm{Na}$ análise do relatório de execução do projeto Saber Mais, Viver Melhor-Pronera, a meta estabelecida para o primeiro período de vigência do projeto, de 2001 a 2003, era a alfabetização de 460 trabalhadores dos assentamentos do Amapá. Para alcançar esta meta, houve a projeção para implantar 23 turmas de EJA, capacitação de 23 educadores e 16 coordenadores para atuarem no Projeto.

Nessa primeira fase, o Pronera atendeu assentamentos dos municípios de Macapá, Santana, Mazagão, Porto Grande, Oiapoque, Tartarugalzinho, Serra do Navio, Calçoene, Amapá e Pedra Branca. As turmas foram organizadas com base na prospecção da demanda de alunos levantada 
pela SEED em parceria com os movimentos sociais, conforme organizado no quadro abaixo:

Quadro 1- Relação dos Assentamentos da Reforma Agrária que receberam o projeto Saber Mais, Viver Melhor em municípios amapaenses

\begin{tabular}{|l|l|c|}
\hline \multicolumn{1}{|c|}{ PROJETO DE ASSENTAMENTO } & \multicolumn{1}{c|}{ MUNICÍPIO } & N$^{\circ}$ DE ALUNOS \\
\hline Matão do Piaçacá & Santana & 40 \\
\hline Piquiazal & Mazagão & 20 \\
\hline Pae Maracá & Mazagão & 40 \\
\hline Pancada do Camaipi & Mazagão & 20 \\
\hline Munguba & Porto Grande & 40 \\
\hline Nova Colina & Porto Grande & 20 \\
\hline Corre Agua & Macapá & 20 \\
\hline Vila Velha do Cassiporé & Oiapoque & 20 \\
\hline Serra do Navio & Serra do navio & 20 \\
\hline Cedro & Tartarugalzinho & 40 \\
\hline Bom Jesus & Tartarugalzinho & 20 \\
\hline Carnot & Calçoene & 20 \\
\hline Lourenço & Calçoene & 20 \\
\hline Cruzeiro & Amapá & 20 \\
\hline Pedra Branca & Pedra Branca do Amapari & 20 \\
\hline Perimetral & Pedra Branca do Amapari & 80 \\
\hline \multicolumn{2}{|l}{} \\
\hline
\end{tabular}

Fonte: Convênio n. 54350.001865/2001-31 - INCRA/SEED, 2001

O Projeto iniciou com as 23 turmas previstas, mas finalizou com 22 e em consequência do alto índice de evasão e desistência, apenas 269 assentados concluíram a etapa de alfabetização - EJA. Conforme consta no relatório do projeto (2004), este fenômeno reflete as dificuldades de acesso às salas de aula, devido à falta de transporte, cansaço físico, problemas de baixa visão em alguns trabalhadores e a desistência de 1 (um) educador que não se identificou com o projeto.

De acordo com o ofício/SR/21/INCRA/n 1220/2005, o convênio entre o INCRA e a SEED para a execução do projeto nos assentamentos amapaenses ficou suspenso por um período, devido a inadimplência do Governo do Estado do Amapá. Após a suspensão da inadimplência, foi liberado o Convênio n 001/2005 SEED/INCRA para a continuidade na oferta da alfabetização EJA nos assentamentos, tendo como vigência o período de 2005 a 2007. 
Consta no Plano de Trabalho da DIEJA/SEED (2005, p. 34) que o projeto intitulado Pronera Escolarização - 2005 tinha como objetivos alfabetizar 100 jovens e adultos; elevar a escolaridade no $1^{\circ}$ segmento ( $1^{a}$ à $4^{\mathrm{a}}$ série) de 825 trabalhadores rurais, em 30 Projetos de Assentamentos do INCRA/AP e os reconhecidos e contribuir para o desenvolvimento rural sustentável. A continuidade do Projeto apoiado pelo Pronera no Estado do Amapá é justificada como uma ação que possibilitaria a inclusão social, a ampliação do nível de escolarização dos assentados e o cumprimento da determinação política de Desenvolvimento com Justiça Social nos assentamentos. A população do campo sempre esteve à margem das políticas sociais e Camacho (2014, p. 456) afirma que:

O PRONERA tem a função de corrigir esta histórica exclusão reduzindo a sua marginalização. Mas, não apenas isso, esta política pública abre a possibilidade de construção de uma identidade de grupo social para os camponeses.

O Projeto apoiado pelo Convênio $n^{\circ}$. 001/2005 SEED/INCRA tinha dentre as metas a oferta de EJA para os dois primeiros segmentos do Ensino Fundamental, sendo o primeiro correspondente às $1^{a}$ e $2^{a}$ séries, com vigência no ano de 2006, e o segundo referente às $3^{a}$ e $4^{a}$ séries a ser ofertado no ano de 2007. Este projeto foi elaborado para abranger 28 Projetos de Assentamentos (P.A) do INCRA/AP em 13 municípios do Amapá.

Para atender a meta estabelecida foi prevista a organização de 33 turmas com o propósito de elevar a escolarização de $100 \%$ da demanda atendida. Consta na Proposta Pedagógica do projeto que:

A implantação da escolarização é resultado do Convênio $\mathbf{n}^{\circ}$. 54250.002346/2004-33, firmado entre a Secretaria de Estado da Educação-SEED e INCRA-AP, [...] a mesma irá abarcar as quatro séries iniciais do Ensino Fundamental-EJA, distribuídas em dois segmentos: o primeiro, correspondendo a $1^{a}$ e $2^{a}$ séries e o segundo, correspondendo a $3^{a}$ e $4^{a}$ séries. Cada uma terá a duração de um ano, com carga horária anual de 800 horas distribuídas em 200 dias letivos. Vale ressaltar que dessas 800 horas, 720 serão destinadas à atividades escolares e 80 horas para atividades extraescolares, como 
oficinas, encontros, palestras, excursões, etc. (DIEJA/SEED, 2005, p. 34).

Quanto à proposta do nível de alfabetização de jovens e adultos foram contemplados 04 P.A, sendo Mutum, Dra Mércia, Pe. Jósimo e Igarapé Grande. Nesta etapa, a meta estabelecida era alfabetizar 100 trabalhadores assentados.

No quadro abaixo, encontra-se a distribuição das turmas e dos P.A atendidos por município.

Quadro 2- Caracterização do Contexto de execução do Projeto Pronera nos P.A dos municípios amapaenses

\begin{tabular}{|c|c|c|c|c|c|}
\hline $\begin{array}{l}\mathrm{N}^{\circ} \text { de } \\
\text { Ord. }\end{array}$ & Município & $\begin{array}{l}\mathrm{N}^{\circ} \text { de } \\
\text { Ord. }\end{array}$ & Assentamento & $\begin{array}{c}\text { Distância } \\
\text { da } \\
\text { Capital KM }\end{array}$ & $\begin{array}{l}\text { Condições de } \\
\text { Acesso }\end{array}$ \\
\hline \multirow[b]{2}{*}{01} & \multirow[t]{2}{*}{ Santana } & 01 & $\begin{array}{l}\text { P.A Matão do Piaçacá I e } \\
\text { II }\end{array}$ & $90 \mathrm{Km}$ & $\begin{array}{l}\text { BR } 156 \text { Ramal } 1 \mathrm{e} \\
2\end{array}$ \\
\hline & & 02 & P.A Anaverapucu & & $\begin{array}{l}\text { Rod. } \\
\text { Macapá/Mazagã } \\
\text { o e Ramal }\end{array}$ \\
\hline \multirow[t]{3}{*}{02} & \multirow[t]{3}{*}{ Mazagão } & 03 & P.A Piquiazal & $80 \mathrm{Km}$ & $\begin{array}{ll}\text { Rod. } & \text { Ramal } \\
\text { Pioneiro } & \end{array}$ \\
\hline & & 04 & P.A Maracá I e II & $125 \mathrm{Km}$ & BR 156 \\
\hline & & 05 & P.A Pancada do Camaipi & $98 \mathrm{Km}$ & Rod/Fluvial \\
\hline \multirow{4}{*}{03} & \multirow{4}{*}{ Porto Grande } & 06 & P.A Munguba le $\|$ & $162 \mathrm{Km}$ & AP 210 \\
\hline & & 07 & P.A Nov a Colina & $114 \mathrm{Km}$ & BR 156 \\
\hline & & 08 & P.A Nov a Canaã & $142 \mathrm{Km}$ & $\begin{array}{l}\text { BR } 210 \text { Perimetral } \\
\text { Norte e Ramal }\end{array}$ \\
\hline & & 09 & P.A Manoel Jacinto & $110 \mathrm{Km}$ & $\begin{array}{l}\text { BR } 210 \text { e Travessia } \\
\text { de Barco no Rio } \\
\text { Araguari. }\end{array}$ \\
\hline 04 & Itaubal & 10 & P.A Itaubal & $48 \mathrm{Km}$ & $\begin{array}{l}\text { BR } 156 \text { e } 65 \mathrm{Km} \text { de } \\
\text { Estrada } \\
\text { Pavimentada }\end{array}$ \\
\hline \multirow{3}{*}{05} & \multirow{3}{*}{ Macapá } & 11 & P.A Corre Agua & $102 \mathrm{~km}$ & BR 156 e Rod. 070 \\
\hline & & 12 & P.A Dra Mércia & $20 \mathrm{Km}$ & BR 156 \\
\hline & & 13 & P.A Pe. Josimo & $30 \mathrm{Km}$ & BR/AP 70 \\
\hline \multirow[t]{2}{*}{06} & \multirow[t]{2}{*}{ Oiapoque } & 14 & P.A Cassiporé & $650 \mathrm{Km}$ & $\begin{array}{lll}\text { BR } 156 \text { e Rio } \\
\text { Cassiporé }\end{array}$ \\
\hline & & 15 & P.A Igarapé Grande & $610 \mathrm{Km}$ & $\begin{array}{lll}\text { BR } 156 \text { e } & \text { Rio } \\
\text { Cassiporé } & & \\
\end{array}$ \\
\hline 07 & Serra do navio & 16 & P.A Serra do navio & $215 \mathrm{Km}$ & AP 210 \\
\hline \multirow{5}{*}{08} & \multirow{5}{*}{ Tartarugalzinho } & 17 & P.A Cedrolell & $220 \mathrm{Km}$ & BR 156 \\
\hline & & 18 & P.A Nova Vida & $140 \mathrm{Km}$ & BR 156 e Ramal \\
\hline & & 19 & $\begin{array}{l}\text { P.A Gov. Janary Gentil } \\
\text { Nunes }\end{array}$ & $200 \mathrm{Km}$ & BR 156 e Ramal \\
\hline & & 20 & P.A Bom Jesus & $230 \mathrm{Km}$ & BR 156 \\
\hline & & 21 & $\begin{array}{lll}\text { P.A São } & \text { Benedito } & \text { do } \\
\text { Aporema } & & \\
\end{array}$ & $173 \mathrm{Km}$ & BR 156 e Ramal \\
\hline 09 & Pracuúba & 22 & P.A Cujubim & $216 \mathrm{Km}$ & BR 156 \\
\hline \multirow[t]{2}{*}{10} & Laranjal do Jari & 23 & P.A Maria Nazaré Mineiro & $256 \mathrm{Km}$ & BR 156 \\
\hline & & 24 & P.A Carnot & $424 \mathrm{Km}$ & BR 156 \\
\hline
\end{tabular}




\begin{tabular}{|l|l|l|l|l|l|}
\hline 11 & Calçoene & 25 & P.A Lourenço & $464 \mathrm{Km}$ & BR 156 \\
\cline { 3 - 6 } & 26 & P.A Mutum & $454 \mathrm{Km}$ & BR 156 \\
\hline 12 & Amapá & 27 & P.A Cruzeiro & $272 \mathrm{Km}$ & BR 156 \\
\cline { 2 - 6 } & 28 & P.A Piquiá & $310 \mathrm{Km}$ & BR 156 e Ramal \\
\hline \multirow{2}{*}{13} & $\begin{array}{l}\text { Pedra Branca } \\
\text { do Amapari }\end{array}$ & 29 & P.A Pedra Branca & $210 \mathrm{Km}$ & AP 210 \\
\cline { 2 - 6 } & 30 & $\begin{array}{l}\text { P.A Perimetral Norte } \\
\text { (Riozinho, Sete IIhas, } \\
\text { Tucano I e II) }\end{array}$ & AP 210 Km \\
\hline
\end{tabular}

Fonte: Projeto Pronera Escolarização EJA - DIEJA/SEED, 2005

No quadro foram organizados os municípios e os P.A selecionados para receber a proposta de alfabetização e de escolarização nos anos iniciais do Ensino Fundamental na modalidade EJA. De acordo com o projeto de implantação, a demanda para a oferta desta modalidade de ensino para os trabalhadores do campo surgiu com o levantamento realizado pelos movimentos sociais que são parceiros da SEED e a Superintendência do INCRA/AP (SEED, 2005).

Conforme a proposta metodológica, o Projeto foi elaborado dentro da concepção freireana de educação popular, pautando-se na formação humana e cidadã em que o sujeito é capaz de transformar a sua comunidade. Outro aspecto a ser considerado é o amparo legal do Projeto embasado na Resolução $n^{\circ}$. 01/2002 do CNE/CEB que estabelece as Diretrizes Operacionais para a Educação Básica das Escolas do Campo (DOEBEC), assim como pelas Diretrizes Curriculares Nacionais da Educação Básica. Além disso, é declarado que a proposta curricular foi adaptada de acordo com as características e particularidades do campo amapaense (SEED, 2005).

Desta forma, o currículo adotado para o projeto de Escolarização EJA Pronera foi estruturado com base nos temas trabalho, organização social e sustentabilidade, organizados em quatro eixos norteadores do projeto (planejamento, execução e avaliação), conforme será representado na figura abaixo: 
Figura 1- Organograma da Proposta Curricular Projeto EJA/Pronera

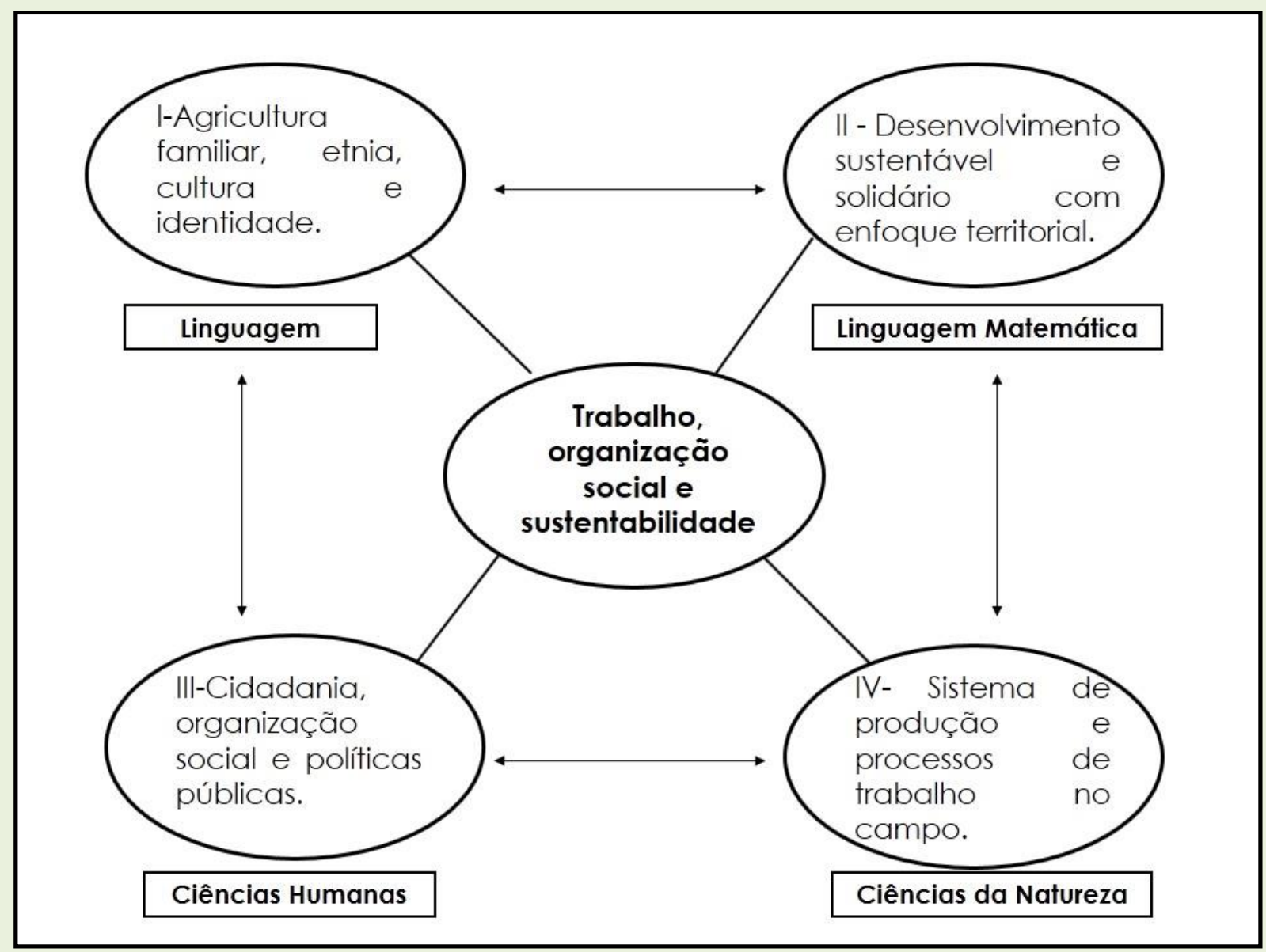

Fonte: Proposta Pedagógica para Implantação da Escolarização - Pronera. SEED, 2005

O currículo proposto procura articular as áreas do conhecimento de forma interdisciplinar, conforme orientação das DOEBEC e da LDB 9.394/1996, que prevê em seu Art. 26 que os currículos da Educação Básica devem ser organizados com uma base nacional comum e uma parte diversificada. Nesta parte diversificada, deve-se contemplar as características regionais e locais de cada comunidade, considerando os aspectos sociais, culturais e econômicos da população do campo (BRASIL, 2013).

Para acompanhar a execução do Projeto a SEED, através da DIEJA, e, em parceria com a Superintendência Regional do INCRA e os movimentos sociais, realizaram acompanhamento técnico e pedagógico com os professores e coordenadores locais, oferecendo formação continuada e 
visitas nos assentamentos em que o Projeto estava em execução (SEED, 2005).

No quadro, encontra-se o resumo da execução do projeto EJAPronera, desde a sua implantação em 2001 até o ano de 2008.

Quadro 3 - Execução do Projeto Saber Mais, Viver Melhor e Projeto Alfabetização e Escolarização EJA-Pronera nos municípios amapaenses

\begin{tabular}{|c|c|c|c|c|}
\hline Convênio & Ano & Meta anual & Concluíram & $\begin{array}{c}\text { Índice de } \\
\text { Evasão }\end{array}$ \\
\hline Alfabetização & $2001 / 2003$ & 460 alunos & 269 alunos & $41,60 \%$ \\
\hline Alfabetização & 2004 & 200 alunos & 175 alunos & $12,5 \%$ \\
\hline $\begin{array}{l}\text { Alfabetização/ } \\
\text { Escolarização }\end{array}$ & $2006 / 2008$ & $\begin{array}{l}100 \text { alunos } \\
825 \text { alunos }\end{array}$ & $\begin{array}{l}21 \text { alunos } \\
294 \text { alunos }\left(1^{a} \text { etapa }\right) \\
96 \text { alunos }\left(2^{a} \text { etapa) }\right.\end{array}$ & $\begin{array}{l}57,14 \% \\
54,90 \%\end{array}$ \\
\hline
\end{tabular}

Fonte: Relatório DIEJA/SEED, 2008

De acordo com as informações contidas no quadro 3, desde a sua origem em 2001, o Projeto EJA-Pronera não conseguiu alcançar as metas estabelecidas. O índice de evasão demonstrado é elevado, sendo que apenas no ano de 2004 esta taxa foi menor que nos demais períodos, atingindo o percentual de $12,5 \%$. O problema da evasão é associado a inúmeros fatores apontados nos relatórios da DIEJA, dentre os quais, a falta de salas de aulas adequadas, o problema de baixa visão dos alunos, a falta de iluminação nos espaços onde eram desenvolvidas as aulas e do transporte, dentre outros.

Nos anos de 2006 a 2008 não houve o cumprimento da meta, que era matricular 825 alunos para as turmas de $1^{a}$ e $2^{a}$ etapas da EJA, e a demanda ficou abaixo de 50\% em 2006. Outro problema revelado nos dados do quadro 3 é a reprovação de alunos nos segmentos do Ensino Fundamental, demonstrando a falta de articulação da SEED na execução do Projeto com a realidade dos P.A selecionados.

No ano de 2008, um novo projeto intitulado "Projeto de Escolarização, em Anos Iniciais do Ensino Fundamental para Assentados do Plano de Reforma Agrária do Estado do Amapá" elaborado pela SEED foi submetido a 
convênio pelo PRONERA. A meta estabelecida era escolarizar 600 assentados nos anos iniciais do Ensino Fundamental. O projeto previa a execução das ações nos anos de 2009 e 2010 em cinco polos: Macapá, Laranjal do Jari, Oiapoque, Serra do Navio e Pracuuba. Estes polos deveriam atender os 16 municípios amapaenses com 28 P.A do INCRA (SEED/AP, 2008).

O projeto teve dentre suas metas a garantia de oferta da $1^{a}$ etapa $\left(1^{a}\right.$ e $2^{a}$ séries) e $2^{a}$ etapa ( $3^{a}$ e $4^{a}$ séries) da EJA para acampados e assentados da Reforma Agrária, na faixa etária a partir de 15 anos de idade. Para a conclusão de cada etapa foram previstos períodos de 15 meses, visto que:

No estado do Amapá, considera-se a excepcionalidade prevista no Manual de Operações do PRONERA, referentes às características físicas e geográficas da região norte, os 15 meses para cada etapa de escolarização justificam-se devido ao período chuvoso da região, que dificulta o acesso e a permanência do educando(a) em sala de aula (SEED, 2008, p. 22).

O diagnóstico e a seleção da demanda para participar do referido projeto ocorreram por meio do levantamento de demanda nos Assentamentos, ações realizadas pelas instituições parceiras, associações, lideranças comunitárias e membros do Colegiado do Pronera (SEED, 2008). Quanto à escolha dos coordenadores locais e dos professores, deu-se por meio da análise de curriculum vitae e entrevista, mas não há definição dos critérios desta seleção no edital analisado.

Para a execução das atividades de ensino e de aprendizagem, o projeto obedeceu à legislação vigente, sendo as DOEBEC e a LDB 9.394/96. Desta forma, a matriz curricular deveria constituir-se de Base Nacional Comum, com a carga horária anual e os componentes curriculares definidos nas diretrizes legais. Assim sendo, a matriz curricular definida para ser utilizada no projeto do Pronera foi a mesma praticada nas turmas da EJA das escolas da zona urbana, conforme demonstrado no quadro. 
Quadro 4 - Matriz Curricular EJA-PRONERA/ Execução 2009/2010 nos municípios do Estado do Amapá

\begin{tabular}{|c|c|c|c|c|}
\hline \multirow{3}{*}{$\begin{array}{l}\text { COMPONENTE } \\
\text { CURRICULAR }\end{array}$} & \multicolumn{4}{|c|}{ CARGA HORÁRIA } \\
\hline & \multicolumn{2}{|c|}{ SEMANAL } & \multicolumn{2}{|c|}{ ANUAL } \\
\hline & $1^{a}$ ETAPA & $2^{a}$ ETAPA & $1^{a}$ ETAPA & $2^{a}$ ETAPA \\
\hline Língua Portuguesa & 05 & 05 & 200 & 200 \\
\hline História & 02 & 02 & 80 & 80 \\
\hline Geografia & 02 & 02 & 80 & 80 \\
\hline Ciências & 02 & 02 & 80 & 80 \\
\hline Matemática & 05 & 05 & 200 & 200 \\
\hline Educação Física & 02 & 02 & 80 & 80 \\
\hline Ensino Religioso & 02 & 02 & 80 & 80 \\
\hline TOTAL & 20 & 20 & 800 & 800 \\
\hline & & & $667 \mathrm{~h} / \mathrm{a}$ & $667 \mathrm{~h} / \mathrm{a}$ \\
\hline
\end{tabular}

Fonte: Relatório DIEJA/SEED, 2008

O projeto em análise tomou como base para a Proposta Pedagógica e as DOEBEC, mas a matriz curricular estabelecida é a mesma utilizada nas turmas de EJA das escolas urbanas, um contrassenso à concepção de Educação do Campo. Na análise de Molina (2008, p. 28) "A complexidade das condições socioeconômicas e educacionais das populações rurais exige maior coerência na construção de estratégias que visem a alavancar a qualidade da Educação do Campo".

Diante desta afirmação de Molina (2008), pode-se tecer uma análise sobre o elevado índice de evasão dos alunos participantes do projeto EJAPronera, uma vez que a educação do campo traz uma concepção que busca criar uma proposta adequada à realidade dos sujeitos e romper com o modelo de educação urbana transferido para as escolas do campo.

Em 2013, um novo convênio foi firmado entre o INCRA e a SEED/AP para fomento através do Pronera do projeto Escolarização em Anos Iniciais do Ensino Fundamental para assentados da Reforma Agrária do Estado do Amapá. A proposta compreendeu o período de agosto de 2013 a outubro de 2015 para o cumprimento do objetivo de alfabetizar 600 assentados.

A proposta foi aprovada e o recurso financeiro liberado para execução das ações. No entanto, os relatórios indicam que até 2015 o projeto não havia sido executado devido à morosidade no processo de 
licitação e a perda de prazos pela SEED para contratação de recursos humanos e materiais. Entretanto, os recursos não foram dev olvidos e o INCRA aguarda a execução do convênio.

Outro convênio do Pronera analisado foi a proposta de curso de Licenciatura Plena em Pedagogia para Educadores e Educadoras da Reforma Agrária do Território da Cidadania do Sul do Amapá. O convênio em questão tinha como objetivo habilitar 100 assentados em Docência em Educação Infantil e Séries Iniciais do Ensino Fundament al.

A previsão de início para execução do projeto era 2009 com encerramento em 2013, sendo que os municípios de Mazagão e Tartarugalzinho seriam contemplados com o curso. Em cada município funcionaria uma turma com 50 alunos, com duração de 4 anos para conclusão da graduação.

O referido curso atenderia uma demanda apresentada pelos movimentos sociais, conforme consta na carta de aceite da RAEFAP. O ofício $n^{\circ}$. 962/2012 SR (21)/AP/GAB afirma que o convênio entre a UNIFAP e o INCRA foi firmado e o projeto aprovado em 2008 para iniciar em 2009, mas não implantado, devido à centralização de recursos e impasses para repasse dos mesmos.

De acordo com o ofício n. 34/2009/DDE, a UNIFAP não conseguiu proceder com o empenho do recurso, devido ao prazo exíguo no final do exercício de 2008 e, consequentemente, procedendo à devolução do recurso em janeiro de 2009. Nos processos $n^{\circ} 54350.001116 / 2008-81$ e $n^{\circ}$. $54350.001204 / 2008-82$, a UNIFAP alegou problemas operacionais enfrentados no exercício de 2008, o que contribuiu para que não ocorresse o empenho dos recursos e a execução do projeto, havendo a devolução de orçamento ao Pronera.

Em 2009, a UNIFAP apresentou novo plano de trabalho, propondo Termo Aditivo, mas após a publicação do Decreto n $.6 .808 / 2009$, o processo foi interrompido, o que impossibilitou o cumprimento do cronograma estipulado pela universidade. 
No ano de 2013, o Instituto Federal de Educação do Amapá (IFAP) submeteu proposta de parceria com o Pronera para a realização do Curso Técnico em Meio Ambiente subsequente ao Ensino Médio para Assentados da Reforma Agrária para a Região Sul do Amapá. O curso foi aprovado e passou a ser executado em 2015, no município de Laranjal do Jari. São parceiros no projeto, O IFAP, O INCRA/AP-Pronera, O Instituto de Desenvolvimento Rural do Amapá (RURAP), o Instituto Chico Mendes de Biodiversidade (ICMBio), Sebrae/AP, a Academia Laranjalense de Letras, Associação de Moradores do Assentamento Nazaré Mineiro, Escola Municipal Maria de Nazaré de Souza Mineiro, Escola Estadual Evilásio Pedro de Lima Ferreira, Associação dos Trabalhadores Agroextrativistas do Alto Cajari (ASTEX-CA), Associação de Mulheres do Alto Cajari (AMAC), Associação dos Trabalhadores Agroextrativistas do Maracá (ASTEX-MA).

Os beneficiários do projeto são os moradores dos assentamentos da Região Sul do Amapá, conforme demanda para a formação profissional técnica. Para isso, a seleção dos alunos ocorreu por meio do edital $n^{\circ}$. 04/2015-Pronera/IFAP-Campus de Laranjal do Jari, que descreve os requisitos para acesso ao curso, sendo que, as comunidades atendidas são o P.A Agroextrativista Maracá, P.A Foz do Mazagão Velho, a Reserva Extrativista do Rio Cajari, Projeto Casulo Nazaré Mineiro, todos os assentamentos do territóro sul do Estado do Amapá, entretanto, dois (Maracá e Foz do Mazagão Velho) são demandas do Programa Assentamentos Verdes (PAV) (IFAP, 2015), conforme dados contidos no gráfico abaixo: 
Gráfico 1- Projetos de Assentamentos (P.A) atendidos com o Curso Técnico em Meio Ambiente nos Municípios de Laranjal do Jari e Mazagão

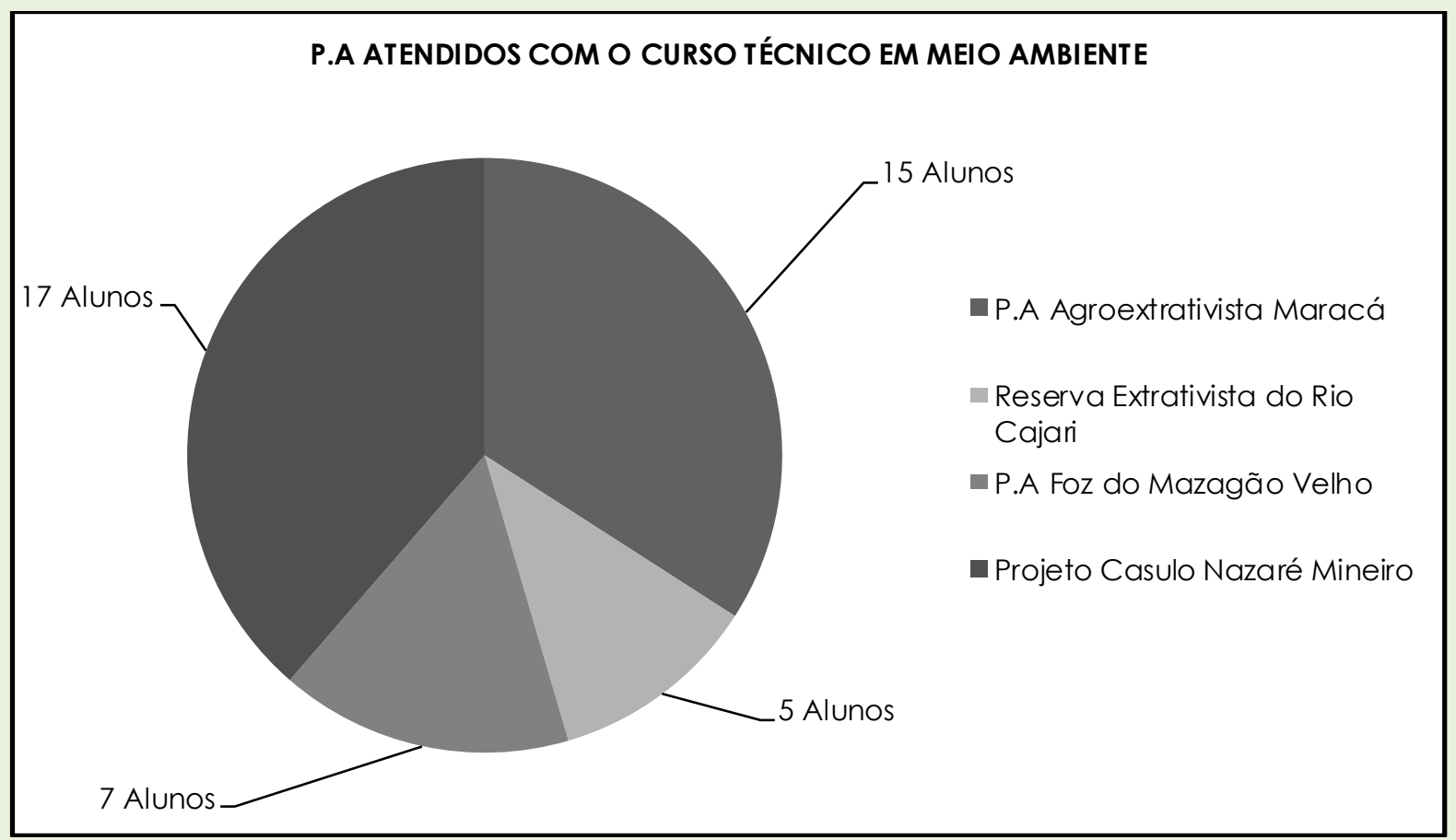

Fonte: Costa, 2016

O curso evidencia a formação de profissionais para atuarem no fortalecimento da agricultura familiar e, para isso, tem como meta formar 44 técnicos em Meio Ambiente. Está organizado em regime presencial e adota a Pedagogia da Alternância como metodologia, pois:

A alternância é o período alternado de vivência e estudo na Escola, na Família e na Comunidade. Nesse sentido, a alternância passa a exercer uma função metodológica e pedagógica no processo formativo dos educandos (JESUS, 2011, p. 9).

O regime de alternância proposto é dividido em Tempo Presencial (TP), composto de 02 módulos previstos para os meses de janeiro e julho e o Tempo Comunidade (TC) que ocorre nos meses de intervalo do TP. Este momento oportuniza a reflexão do educando sobre os conteúdos trabalhados durante as aulas presenciais, integrando os saberes formais e empíricos à prática. 
O referido curso está organizado em 04 módulos presenciais, sendo 02 módulos anuais, obedecendo uma carga horária anual de $1.450 \mathrm{~h}$. Na especificação do projeto:

\begin{abstract}
O técnico em Meio Ambiente colabora na elaboração de laudos, relatórios e estudos ambientais; auxilia na elaboração, acompanhamento e execução de sistemas de gestão ambiental; atua na organização de programas de educação ambiental, de conservação e preservação de recursos naturais, de redução, reuso e reciclagem; identifica as intervenções ambientais, analisa suas consequências e operacionaliza a execução de ações para preservação, conservação, otimização, minimização e remediação dos seus efeitos (IFAP, 2013, p. 12).
\end{abstract}

O Curso Técnico em Meio Ambiente é uma proposta de qualificação dos trabalhadores assentados, sendo um espaço para a construção de conhecimento que considere o contexto e a cultura local, respeito ao ambiente físico, valorização dos sujeitos e de seu modo de vida. Diante disso, é válido ponderar que o curso apresenta-se como elemento para o desenvolvimento local.

Considerando as especificidades do campo na Amazônia Amapaense e a ausência de políticas sociais que venham suprir carências de saúde, transporte, educação, dentre outros, os projetos apoiados pelo Pronera são um importante avanço para os trabalhadores dos assentamentos no Brasil. O Pronera permite à população do campo o acesso aos diferentes níveis da educação básica e superior.

\title{
CONSIDERAÇÕES FINAIS
}

A Educação do Campo nasceu de um movimento emancipatório, que trouxe a normatização e a institucionalização de programas e diretrizes para subsidiar o currículo das escolas do campo. As primeiras manifestações acerca dessa nova concepção de educação mostraram a necessidade de planejar, propor e elaborar políticas contextualizadas com a realidade das comunidades rurais. 
A reestruturação do capitalismo, pautada no reajuste da economia e nos impactos da globalização acentuou as desigualdades de acesso aos direitos sociais, deixando os sujeitos do campo cada vez mais vulneráveis à exclusão e ao analfabetismo. Apesar das conquistas de direitos no âmbito legal, constatou-se durante a pesquisa que a garantia destes se dá, quase, exclusivamente, pela obrigatoriedade e reivindicação dos movimentos sociais. Diante disso, considera-se que, no Brasil, as lutas sociais foram essenciais para assegurar direitos básicos para as populações do campo.

A visibilidade da Educação do Campo enquanto paradigma contrahegemônico é revelada na luta dos movimentos sociais e por diretrizes legais, de âmbito nacional. Entretanto, ao mesmo tempo em que há o discurso oficial e legal da política educacional, ainda permanece um cenário de exclusão das populações do campo no Brasil, o que reflete na baixa escolaridade e na dificuldade de efetivação dessa política.

A história da Educação demonstrou contradições constantes na oferta de ensino para os sujeitos do campo, visto que, em muitos momentos, esse direito Ihes foi negado, vindo a ser amplamente discutido após os anos 1990 , quando muitas políticas públicas passaram a ser elaboradas pelos Movimentos Sociais Camponeses e o Estado.

Nesse contexto, desde 1990, a educação passou a figurar entre as pautas de reivindicações dos movimentos camponeses no Brasil. O processo educativo foi compreendido como um importante aliado no protagonismo da luta pela terra e como elemento para assegurar direitos sociais negados aos trabalhadores do campo. Isto é resultado de mudanças identitárias gestadas nas lutas sociais, cuja visibilidade começa a tomar forma e refletir em ações afirmativas traduzidas, principalmente, na democratização do acesso à educação básica e superior.

O desenvolvimento da pesquisa permitiu visualizar a realidade apenas de um recorte do ensino público ofertado nas escolas do campo no Estado do Amapá, por meio da análise de documentos de implementação do Pronera, o que ampliou as reflexões sobre a necessidade de que as políticas 
públicas de educação alcancem as comunidades rurais, pois as propostas curriculares utilizadas no Programa ainda são uma cópia dos currículos elaborados para a realidade das escolas urbanas.

Consideramos o Pronera uma política pública que deu visibilidade à educação dos sujeitos do campo e vem contribuindo para romper com situações de exclusão socioeconômica, política, cultural e educacional que estão postas em nossa sociedade e que favorecem a manutenção das desigualdades sociais no campo.

A análise dos documentos sobre o Pronera no Estado do Amapá evidenciou que os projetos, em sua maioria, atenderam à modalidade da Educação de Jovens e Adultos, na Educação Básica e foram desenvolvidos pela Secretaria de Estado da Educação e, no Instituto Federal de Educação foi efetivado um curso técnico em nível médio, ainda em fase de conclusão.

Como o Pronera apoia cursos nos níveis da educação superior, acreditamos que as discussões sobre esse Programa precisam avançar no contexto amapaense e, com isso oportunizar o acesso dos trabalhadores do campo dos Projetos de Assentamentos da Reforma Agrária à escolarização em todas as etapas da educação. Nesse sentido, o Pronera é uma importante política de Educação do Campo que pode apoiar cursos em diferentes áreas do conhecimento, conforme demandas da população do campo, mas não conseguiu avançar no âmbito das IES públicas no Estado do Amapá e inúmeros trabalhadores assentados permanecem desassistidos pelas políticas sociais.

Os limites e desafios impostos à elaboração e execução do Pronera na realidade amapaense precisam ser apontados por meio de ensaios no campo teórico a fim de contribuir com outras discussões sobre um novo projeto de educação para o campo junto aos movimentos sociais camponeses do estado e aos órgãos governamentais. É indispensável a elaboração e implementação de propostas de Educação do Campo que se materializem, viabilizando condições de democratização e permanência 
da população dos assentamentos da Reforma Agrária nas salas de aula, dando continuidade aos estudos, conforme previsto na LDB vigente.

\section{REFERÊNCIAS}

ANDRADE, M. R.; DI PIERRO, C. M. A Educação na Reforma Agrária em Perspectiva: uma avaliação do Programa Nacional de Educação na Reforma Agrária. São Paulo: Ação Educativa, 2004.

BRASIL. Decreto $n^{\circ} . \mathbf{7 . 3 5 2}$, de 4 de novembro de 2010. Dispõe sobre a política de educação do campo e o Programa Nacional de Educação na Reforma Agrária - PRONERA. Disponível em: http://www.planalto.gov.br/ccivil_03_/Ato20072010/Decreto/D7352.htm>. Acesso em: 26 fev 2016.

BRASIL. Ministério de Educação e Cultura. LDB - Lei $\mathbf{n}^{\circ}$. 9394/96, de 20 de dezembro de 1996. Estabelece as diretrizes e as bases da Educação Nacional. Brasília: MEC. $8^{a}$ edição, 2013.

BRASIL. Programa Nacional de Educação na Reforma Agrária (PRONERA). Manual de Operações. Brasília-DF, 2004.

BRASIL. Programa Nacional de Educação na Reforma Agrária (PRONERA). Manual de Operações. Braślia-DF, 2011.

BRASIL. Educação do Campo: marcos normativos. Brasília - Programa Nacional de Educação na Reforma Agrária (PRONERA). Manual de Operações. Brasília-DF, 2014.

CAMACHO, R. S. Paradigmas em disputa na educação do campo. 2014. $806 f$. Tese (Doutorado em Geografia) - Universidade Estadual Paulista, Faculdade de Ciências e Tecnologia - Presidente Prudente, 2014.

COSTA, H. G. P. da. Políticas públicas de educação: um estudo sobre os programas federais de educação para o campo no Amapá. $134 \mathrm{f}$. Dissertação (Mestrado em Desenvolvimento Regional). UNIFAP, Macapá, 2016.

HAGE, S. M. Por entre águas, campo e floresta: a contribuição do Pronera para a democratização da educação superior nos assentamentos rurais da Amazônia paraense. $36^{a}$ Reunião Nacional da ANPEd - 29 de setembro a 02 de outubro de 2013, Goiânia-GO.

IFAP. Projeto Curso Técnico em Meio Ambiente pata Educandos de Assentamentos da Reforma Agrária da Região Sul do Amapá-forma subsequente ao Ensino Médio. Macapá, 2013.

MOLINA, M. C.; JESUS S. M. S. A. de. Contribuições do PRONERA à Educação do Campo no Brasil. Reflexões a partir da tríade: Campo - Política Pública Educação. In: SANTOS, C. A. dos. MOLINA, M. C.; JESUS, S. A. (org.). Memória e História do PRONERA. Brasil, 2011. 
MOLINA, M. C. A constitucionalidade e a justicibilidade do direito à educação dos povos do campo. In: SANTOS, C. A. dos (Org.). Por uma educação do campo: Campo - Políticas Públicas - Educação. Braślia: INCRA; MDA, 2008.

MOLINA, M. C. A contribuição do PRONERA na construção de políticas públicas de educação do campo e desenvolvimento sustentável. Brasília, 2003. Tese (Doutorado em Educação) Universidade de Brasillia. http://www.unbcds.pro.br/publicacoes/MonicaMolina.pdf

SEED. Convênio INCRA/SEED. Projeto Alfabetização de Jovens e Adultos 2005/2007. Macapá, 2005.

SEED. Relatório de Acompanhamento do Projeto Saber Mais, Viver Melhor Pronera/Amapá. Macapá, 2008.

SOUZA, M. A. de. Educação do Campo: Propostas e Práticas Pedagógicas do MST. Petrópolis, RJ. Vozes, 2012.

Recebido em: Novembro de 2016 Aceito em: Abril de 2017 